\title{
Rapport annuel 2013
}

Au cours de l'exercice écoulé, la Caisse de secours des médecins suisses a accordé son soutien à 15 médecins tombés malgré eux dans le besoin (ils étaient 21 en 2012) ainsi qu'aux proches et aux descendants de médecins décédés.

Pendant la même période, la Caisse a cessé d'apporter son aide à trois personnes. Toujours en 2013, deux nouveaux cas sont venus s'ajouter à la liste des bénéficiaires.

Les produits ont résulté des recettes provenant de dons pour un montant de 116045 CHF (2012: $115277 \mathrm{CHF}$ ) ainsi que des intérêts et des dividendes du capital de la fondation, à hauteur de 78919 CHF.

Concernant les charges, les contributions de soutien que nous avons versées ont atteint le montant de 131500 CHF (2012: 198550 CHF). Les dépenses relatives à la gestion de la Caisse de secours et à l'administration de la fortune se sont élevées à 48808 CHF.

En 2013, la différence entre les recettes provenant de dons ainsi que des intérêts et dividendes du capital et les charges consécutives aux contributions de soutien et aux dépenses administratives a constitué un surplus de recettes de 16362 CHF.

La fortune de la fondation consiste en un mélange d'obligations et d'actions satisfaisant aux prescriptions de la prévoyance professionnelle (LPP). L'apport d'actions en provenance de la succession du Dr Wadim Rorschach a provoqué un surplus de dividendes. Ce déséquilibre sera corrigé au fil du temps.

Le compte d'exploitation, le bilan et la gestion de

Dr U. Lüscher

Président de la Commission de fondation

Gellertstrasse 144

CH-4052 Bâle
Les membres du Conseil de fondation exercent leur activité à titre bénévole.

Les dons individuels inférieurs à $500 \mathrm{CHF}$ forment le pilier traditionnel de notre fondation. Afin de réduire nos frais administratifs au strict minimum, nous renonçons à remercier personnellement les donateurs. Qu'ils veuillent trouver ici l'expression de notre vive gratitude.

Les comptes annuels de la Caisse de secours ont été révisés par la fiduciaire Axt Treuhand qui les a trouvés conformes aux règles. Nous la remercions cordialement de son travail. Le lecteur intéressé trouvera des informations détaillées sur les comptes annuels dans le bilan et le compte d'exploitation publiés ci-après.

Nous remercions vivement Messieurs J. Kobler et W. Mahrer de la Banque La Roche 1787 pour la tenue de la comptabilité et la gestion de la fortune.

La composition du Conseil de fondation est restée la même. Depuis 2014, le Dr Urs Lüscher occupe la fonction de président et le Dr Urs Leibundgut celle de trésorier.

La Commission de fondation de la Caisse de secours des médecins suisses:

Dr U. Lüscher, président

DrS. Stöhr

Dr U. Leibundgut, trésorier

Compte postal de la Caisse de secours des médecins suisses: 40-644-3 Bâle 


\section{Comptes annuels (en francs)}

\author{
Bilan au 31 décembre 2013 \\ Comptes Banque La Roche \\ Compte postal \\ Débiteur impôt anticipé \\ Titres \\ Compte de régularisation des passifs \\ Provision sur titres \\ Fortune au 31 décembre 2013 \\ Caisse de secours au $1^{\text {er }}$ janvier 2013 \\ Changement de l'exercice
}

Compte d'exploitation pour 2013

Dons

Revenu sur capital

Revenu divers

Ajustement provision sur titres

Pertes sur titres (réal.)

Ajustement change

Contributions

Frais de banque et d'administration

Bénéfice de l'exercice

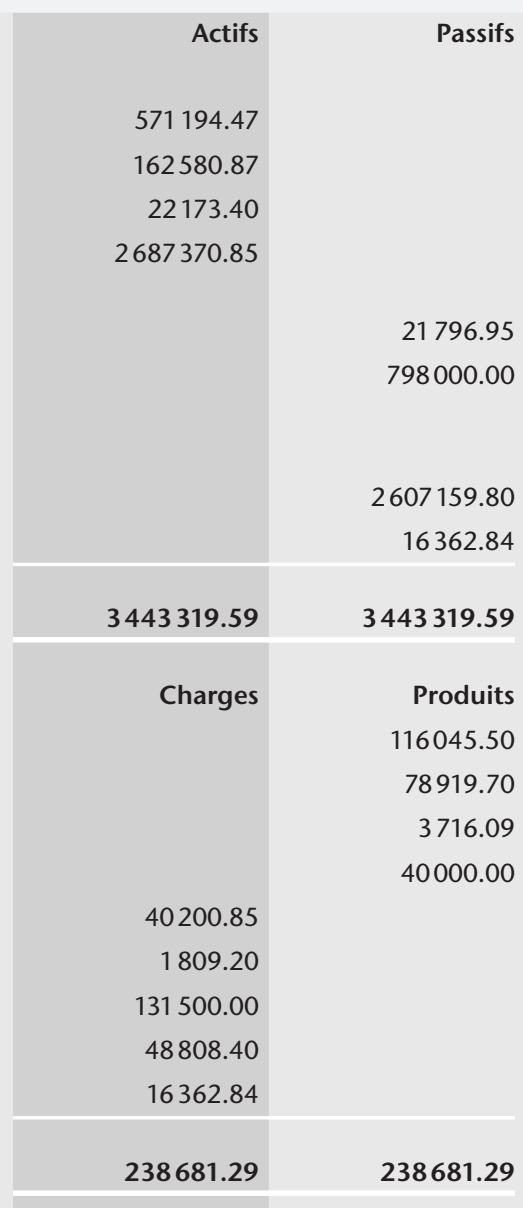

